\title{
Transdisciplinary Integrated Curriculum: An Analysis of Teacher Experiences through a Design Model within the Framework of IB-PYP
}

\begin{tabular}{|c|c|}
\hline \multicolumn{2}{|c|}{$\begin{array}{l}\text { Burcu Gürkan* } \\
\text { Faculty of Education, Hasan Kalyoncu University, Gaziantep, Turkey } \\
\text { ORCID ID -0000-0003-3942-6407 }\end{array}$} \\
\hline Article history & The purpose of the study is to examine the positive and \\
\hline $\begin{array}{l}\text { Received: } \\
06.05 .2020\end{array}$ & $\begin{array}{l}\text { negative experiences of teachers through a model in the } \\
\text { process of designing a transdisciplinary integrated curriculum }\end{array}$ \\
\hline $\begin{array}{l}\text { Received in revised form: } \\
30.08 .2020\end{array}$ & $\begin{array}{l}\text { within the framework of IB-PYP. The design of the study } \\
\text { included a holistic, multiple-case approach. The study was }\end{array}$ \\
\hline $\begin{array}{l}\text { Accepted: } \\
13.09 .2020\end{array}$ & $\begin{array}{l}\text { carried out with } 50 \text { teachers, among which } 7(14 \%) \text { are male } \\
\text { and } 43(86 \%) \text { are female, in the IBEC teacher curriculum at a } \\
\text { university in Turkey in the } 2018-2019 \text { spring and } 2019-2020\end{array}$ \\
\hline Key words: & fall academic terms. IBEC was given in Istanbul, Ankara, and \\
\hline $\begin{array}{l}\text { Transdisciplinary } \\
\text { instructional design; } \\
\text { Integrated curriculum; } \\
\text { Teacher education }\end{array}$ & $\begin{array}{l}\text { Gaziantep cities in Turkey. The data were collected with } \\
\text { researcher diary, focus group interviews and reflective } \\
\text { writings, and analyzed through content analysis. In the study } \\
\text { in which the transdisciplinary integrated curriculum was } \\
\text { designed using a model, it was observed that the model } \\
\text { brought systematic approach to teachers. The integrated } \\
\text { curriculum design was realized through the cooperation of } \\
\text { teachers from different branches, which proved to be efficient } \\
\text { to cooperate with different disciplines. Emphasizing that they } \\
\text { had difficulty in selecting practices for planning and } \\
\text { evaluating the teaching process, the participant teachers also } \\
\text { affirmed that specifically these stages developed them } \\
\text { professionally. In designing the program, teachers also } \\
\text { developed coping skills. It is understood that the } \\
\text { brainstorming technique relieved teachers' challenges. It was } \\
\text { found that teachers' experiences were of significance in } \\
\text { effective design of the integrated programs. School-based } \\
\text { program development, collaborative work, and the ability to } \\
\text { meet the needs of different disciplines with a common } \\
\text { mechanism were become evident over time. }\end{array}$ \\
\hline
\end{tabular}

* Correspondency: burcu.gurkan@hku.edu.tr 


\section{Introduction}

Information is an important product of society, generated and used to understand the world. Bruner (1975) expresses the view that disciplines are necessary for knowledge acquisition while Campbell (1969) states that being in one discipline is complicated and challenging for scientific productivity. While disciplines produce information related to the methods of the very field, the information is necessary for different disciplines with a produced phenomenon, hypothesis, theories, opinions, questions, perspectives and solution recommendations. Additionally, disciplines must intersect to understand complex problems, solve these problems and to holistically perceive the universal reality. How information is produced by a discipline will be taught is just as important as the production of that information itself. Separate or integrated teaching of a discipline reflects the nature and philosophy of the knowledge and the teaching approach.

Gibbons (1979) argued that in subject-based programs, it might seem natural to integrate fields to create interdisciplinary concepts. The integrated curriculum represents an approach that argues for connecting real-life situations with different disciplines. An integrated curriculum focuses on the setting, needs, concerns and individual or social problems, on forming a connection with the real world and on participating in meaningful activities (Beane, 1995; Jacobs, 1989, 1991; Vars, 1991). In integrated curriculums, disciplines are combined in different ways and the limits of disciplines are related to content organisation. Erickson (1994) argues that it is attractive to decrease content load by integrating subjects, but this is not easy. Beane (1995) believes that an integrated curriculum is not simply an organisational tool related to changes in the curriculum. Rather, it is a new way of thinking about the role of the school, the program resources, and the use of knowledge in an integrated curriculum approach. Akins and Akerson (2002) emphasise the challenges for students to understand the connections between disciplines without understanding the nature of disciplines. In this context, it is possible to say that integrated curriculums are not based on a superficial purpose, such as profiting by combining classes, but are instead based on an approach that emphasises a holistic approach to knowledge.

Forming interdisciplinary connections and discovering these connecting paths is important for students (Boyer, 1995). The purpose of integrated curriculums is to better clarify the concepts related to a theme, problem, or situation, to ensure student learning through higher-level thinking processes and to support the formation of different connections between themselves and the world (Erickson 1994; Wall \& Leckie 2017). Schumacher (1995) states that in an integrated curriculum work themes are created by the teachers and students, that themes are based on individual and social concerns, that student questions are important, that learning is based on authentic experiences and that themes are investigated by using primary resources. Additionally, integrated curriculums enable students to understand how usable knowledge is for daily life, they hold students' attention and keep them motivated, they facilitate new knowledge accumulation and ensure meaningful learning and they facilitate teachers' multiple intelligence activity development (Bintz \& Monobe 2018; Brough, 2007, 2012; Drake \& Burn, 2004; Fogarty \& Stoehr, 1995; Hammond, 2017; Nolan \& McKinnon, 2003; Tucker, Hafenstein, Jones, Bernick \& Haines 1997). The main focus of integrated curriculums is a student-centric teaching approach. Students' interests, curiosity, talents, and questions are all necessary and development opportunities guide the learning process. In this way, students are encouraged to see the bigger picture. 
Perception of the whole is a characteristic in human nature, making transdisciplinary pedagogy a viable one. That being said, as Beane (1995) says, children do not need to know the interdisciplinary classification and they do not divide their daily lives into sections. In fact, the tendency for integrating disciplines is not new. These tendencies change depending on integration levels and they reflect the relevant curriculum. The process that started with the disciplinary approach was classified into "multidisciplinary, cross-disciplinary, interdisciplinary and transdisciplinary" integration (Choi \& Pak, 2006; Drake, 2004; Erickson, 1994; Mathison \& Freeman, 1997; Kysilka, 1998; McPhail, 2018; Park \& Son, 2010). Nevertheless, it should not mean that a transition from a disciplinary approach to a transdisciplinary understanding is more important or effective. It is impossible to mention about the existence of other design models without disciplines. The classification types dealt here are only related to the extent to which different disciplines are combined. In short, the bond among disciplines is often a result of an understandingand, sometimes it is a necessity. The explanations about the design models and program focuses below are made according to the degree of combining the disciplines:

- Multidisciplinary design model: In this design, multiple disciplines focus without going beyond their own specializations. The connections between the disciplines are low as there are separate teachings for each discipline (Choi \& Pak, 2006; Drake, 2007).

- Cross-disciplinary design model: In this design, one discipline is viewed from the perspective of another discipline (Meeth, 1978). Since there is no balance between the disciplines in the cross-discipline model, one discipline dominates. In this design, interdisciplinary communication decreases (United Nations Educational, Scientific and Cultural Organization [UNESCO], 1986).

- Interdisciplinary design model: In this design, there is a clearer connection between two or more disciplines. Disciplines integrate to explain a common action, concept, or skill. While the borders between the disciplines are blurred, mutual interactions are high (Berger, 1970; Choi \& Pak 2006; Drake, 2007; Park \& Son, 2010).

- Transdisciplinary design model: Here, disciplines work together in examining real-life problems. The borders of the disciplines are blurred and disciplines cannot be distinguished. The process is executed based on students' questions (Choi \& Pak 2006; Drake, 2007; Meeth, 1978; Rosenfield, 1992).

There are studies on the preparation, implementation, and effects of integrated curriculums. Review of the related literature shows study areas such as the challenges and opportunities of globally integrated curriculums (Ferguson-Patrick, Reynolds \& Macqueen, 2018); student learning and participation in integrated curriculum (LaMotte, 2018) and effects on primary school learning (Hammond, 2017); the impact of a social science class integrated with dance and anthropology on students' knowledge and attitude (Smith, Hodges Kulinnab, Vissicaroc \& Fredrickson, 2016); teachers' perception of the integrated curriculum approach (Tudor, 2014); democratic principles for a student-centric integrated curriculum (Brough, 2012); and the effect on academic success (Romance \& Vitale, 2012). In this study, it is pinpointed that the teachers' experiences in the process of designing a transdisciplinary integrated curriculum are described within a reference frame. 


\section{Transdisciplinary Instruction and the Teacher's Role}

Transdisciplinary teaching is an integrated approach based on analyzing real-life problems with inquiry (Drake, 2007; Herro \& Quigley, 2017). In all processes based on a transdisciplinary approach, the borders between disciplines are eliminated and the disciplines take a more flexible and permeable form. Some problems and situations are within the scope of multiple fields and necessitate highly complex evaluation. The integration of different perspectives both leads to the existence of a transdisciplinary approach and creates a new scope of inquiry in the learning process. Campbell (1999) underpins the need for an integrated curriculum to be structured in a skill-oriented manner and to concentrate on the gradual learning of necessary skills. The focus of a transdisciplinary curriculum is inquiry and the inquiry process involves problem-solving. Questions such as what is the subject?, how do students want to learn?, what are their interests? and which questions are on their minds? form the key to this approach. Students try to understand the unlimited problems of real-life through inquiry. They are expected to form knowledge through activities such as collecting, organising and presenting data, etc. For example, the question "how do we benefit from sunlight?" is related to multiple disciplines such as geography, biology, mathematics and physics; therefore, this question is comprehensive and based on question-solving.

A transdisciplinary approach is used for providing a holistic experience for students' cognitive, social, emotional, and physical development (Amaliyah, Sapriya \& Maryani, 2017). Students that learn to look at any case from various perspectives develop a transdisciplinary understanding. These approaches are formed by creating connections between humans, symbols, realities, authentic experiences, learning to learn, taking risks and high-level thinking (Augsburg, 2014; Jeder, 2014; Marshall, 2014; Nicolescu, 2012). Additionally, Broersma (2014) states that with a transdisciplinary approach, students cooperate in group work and develop respect toward the different disciplines. With transdisciplinary teaching approaches, students develop various self-oriented and social skills during their individual and group work.

In the transdisciplinary learning process, teachers are as much learners as the students are. According to Park and Son (2010), in the transdisciplinary learning process, the student has the role of creating knowledge and the teacher has the role of ensuring interactive learning. Williams, Connell, White and Kemper (2003) state that transdisciplinary teaching is affected by the synergy between students and teachers. Besides, this teaching approach includes elements such as cooperation, social justice, knowledge transformation, technology, teacher and student interaction and authentic experiences. Wall and Leckie (2017) emphasise that teachers can integrate topics and themes that are determined together with students into curriculum study units.

It is difficult to structure an instructional plan beforehand in transdisciplinary instruction because the learning process consists of both teachers' designs and what students want to do. Teachers are expected to design, prepare, and implement the plans. Teachers must constantly develop, assess, and transform a transdisciplinary curriculum into an inquirybased teaching plan before, during and after the process. Also, teachers must consider the themes of classes and their relation to each other rather than abstract forms of them when teaching a transdisciplinary inquiry-based instruction (Giri, 2002). These curriculums must be prepared in cooperation with teachers and different disciplines must work together to create the whole. Huizinga (2009) accentuates that teachers must have general design expertise such as intrinsic, interpersonal and process skills and special design 
expertise such as curriculum design and coherence, subject-matter knowledge and pedagogic knowledge within the curriculum design process (as cited in Huizinga, Handelzalts, Nieveen \& Voogt, 2014). In the transdisciplinary instruction preparation process, teachers must have knowledge of disciplines, curriculum design and assessment and the properties of student development and they must have cooperative working skills.

The research was carried out in Turkey where public primary, middle and high school curriculums are developed by a central management and notified to schools to apply. Thus, teachers working at public schools are only the practitioners of the curriculum. On the other hand, private schools can design their own teaching programs/curriculums that adhere to the attainments of the central program. In this sense, they hold a more flexible understanding than public schools and can develop their curriculum considering the school needs. Teachers working in private schools develop their skills to design the teaching process while performing their professions, since there are not any compulsory courses such as school-based program development or instructional design in education faculties. For this reason, it can be inferred that the design and development of the curriculum in collaboration with teachers is not possible for teachers and prospective teachers. Curriculums can be developed with a school-based and collaborative work approach, which is not a novel notion.

In a review of the related literature, it was found that there were studies in which collaborative work was assessed in designing a program (Miller, 2013; Tallman, 2019); the factors affecting the development of teachers working in schools where transdisciplinary integrated programs were prepared and applied, were analyzed (Cook, 2015), and the changes in their experiences (Savage \& Drake, 2016) as well as in philosophies (Getchell, 2010; Holeva, 2012) were also investigated. In addition, there were studies in which integrated program application policies were evaluated considering teachers' opinions (Drake, Savage, Reid, Bernard \& Beres, 2015; Özer, 2010). Yet it is notable that a model showing how teachers can develop transdisciplinary integrated programs was not found in the literature. It is well known that all integrated program designs, including transdisciplinary ones, require teachers' cooperation. The power of cooperation is undeniably important.

The focus of the research was to determine the teacher benefits from designing a transdisciplinary integrated curriculum. This focus point was based on the transdisciplinary integrated curriculum design model. The main issue is how a design can be carried out on a model and how the experiences will influence teachers. Thusly, it was ensured to examine teacher experiences in a systematic way during the process, which is the unique aspect of the research. The designed model is also so flexible that it can be used in the development of many other transdisciplinary teaching practices. Hence, it is believed that it can guide teachers in designing the PYP framework program, which serves a wide audience, or any teaching process based on integrated program design. Within this context, the general purpose of this study is to analyse teachers' transdisciplinary inquiry-based instruction experience in detail. During the research the answer to: "What are the experiences that teachers have when designing transdisciplinary integrated teaching in the context of the PYP framework?" was sought.

\section{Methods}

This study uses a holistic multiple case approach pattern. A case study is a research approach that enables analysis and explanation of a certain case or case group 
with qualitative and quantitative data. This approach contributes to our knowledge of individual, group, organisational, social and political events. In holistic multiple case patterns, events that can be perceived as holistic on their own are investigated (Yin, 2008; Yin, 2011). In this study, the experiences of three different teacher groups on designing transdisciplinary integrated curriculum were thoroughly examined and evaluated.

\section{Sample}

This study was conducted with a total of 50 teachers, 7 (14\%) male and $43(86 \%)$ female, on the IBEC [International Baccalaureate Education Certificate] teacher training program in a university in Turkey during the 2018-2019 spring and 2019-2020 fall academic terms. IBEC training is given in the cities of İstanbul, Ankara and Gaziantep, Turkey. Table 1 provides study group information:

Table 1. Demographic information of participants.

\begin{tabular}{|c|c|c|c|c|c|c|c|c|}
\hline Cases & $\begin{array}{l}\text { Participant } \\
\text { Group }\end{array}$ & Gender & Age & Dept. & $\begin{array}{l}\text { Participant } \\
\text { Group }\end{array}$ & Gender & Age & Dept. \\
\hline \multirow{6}{*}{ 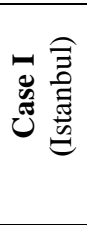 } & P1-G1 & Male & 24 & RE & P6-G2 & Female & 37 & ET \\
\hline & P2-G1 & Female & 47 & PST & P7-G2 & Female & 24 & TLL \\
\hline & P3-G1 & Female & 26 & PT & P8-G3 & Female & 30 & SÖ \\
\hline & P4-G1 & Female & 22 & ET & P9-G3 & Female & 53 & VA \\
\hline & P5-G2 & Male & 28 & TÖ & P10-G3 & Female & 26 & FB \\
\hline & P11-G4 & Female & 29 & PST & P18-G5 & Female & 24 & PCG \\
\hline \multirow{6}{*}{ 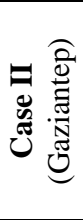 } & P12-G4 & Male & 27 & PST & P19-G6 & Female & 22 & PST \\
\hline & P13-G4 & Male & 31 & PST & P20-G6 & Female & 21 & ET \\
\hline & P14-G4 & Female & 27 & MT & P21-G6 & Female & 21 & PCG \\
\hline & P15-G5 & Female & 27 & SÖ & P22-G6 & Female & 23 & PT \\
\hline & P16-G5 & Female & 26 & ET & P23-G6 & Female & 23 & PST \\
\hline & P17-G5 & Male & 28 & PST & & & & \\
\hline \multirow{14}{*}{ 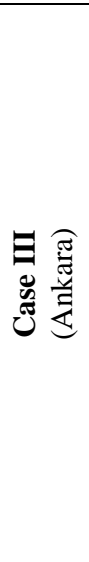 } & P24-G7 & Female & 24 & ET & P38-G10 & Female & 25 & BïÖ \\
\hline & P25-G7 & Female & 22 & ET & P39-G10 & Female & 53 & PST \\
\hline & P26-G7 & Female & 39 & PT & P40-G11 & Female & 23 & PST \\
\hline & P27-G7 & Female & 24 & PT & P41-G11 & Female & 60 & PST \\
\hline & P28-G8 & Female & 33 & PT & P42-G11 & Female & 24 & ET \\
\hline & P29-G8 & Female & 30 & PT & P43-G11 & Female & 33 & ET \\
\hline & P30-G8 & Female & 25 & ET & P44-G11 & Female & 53 & PS \\
\hline & P31-G8 & Female & 35 & ET & P45-G11 & Female & 28 & PT \\
\hline & P32-G8 & Female & 29 & ET & P46-G12 & Female & 24 & ET \\
\hline & P33-G9 & Male & 27 & ET & P47-G12 & Female & 32 & PT \\
\hline & P34-G9 & Female & 57 & PST & P48-G12 & Female & 27 & VA \\
\hline & P35-G9 & Female & 30 & $\mathrm{BT}$ & P49-G12 & Male & 28 & DR \\
\hline & P36-G10 & Female & 35 & SST & P50-G12 & Female & 23 & ET \\
\hline & P37-G10 & Female & 25 & VA & & & & \\
\hline
\end{tabular}

Dept: Department; BT: Biology Teaching; ITT: Information Technology Teaching; RE: Religion Education; DR: Drama; S: Science; VA: Visual Arts; ET: English Teaching; MT: Mathematics Teaching; PT: Preschool Teaching; PCG: Psychological Counselling and Guidance; PST: Primary School Teaching; SST: Social Sciences Teaching; TLL: Turkish Language and Literature; TT: Turkish Teaching

The course represented as Case I was organised in Istanbul and involved 10 participants ( 2 male, 8 female). For the study, three different teams were created (G1, G2 and G3). The course represented as Case II was organised in Gaziantep comprising of 13 participants ( 3 male, 10 female). For the study, three different teams were created (G4, G5 and G6). The course represented as Case III was organised in Ankara which was 
composed of 29 participants ( 2 male, 27 female). For the study, five different teams were created (G7, G8, G9, G10, G11 and G12). Each group included participants from different branches/disciplines.

\section{IB [International Baccalaureate] and IBEC Curriculum}

IB is an organization that carries on educational activities with more than 5000 schools they support worldwide (International Baccalaureate Organisation [IBO], 2020). The education of students between the ages of 3 and 12 is provided under the PYP [Primary Years Program]. And there are over 1800 PYP schools worldwide (IBO, 2020). PYP education is based on the transdisciplinary learning approach. The transdisciplinary teaching approached is planned and applied with the thematic approach. Teachers have the roles of course designer and implementer. Students discover knowledge with research and inquiry with the teacher's guidance. Teachers design lesson plans consisting of "main idea, concepts, connected concepts, action, learner profile, line of inquiry, previous learning, student questions, teacher questions" elements (IBO, 2018a). Students gain real-life experience with transdisciplinary themes organised in the form of "Who we are, Where we are in place and time, How we express ourselves, How the world works, How we organize ourselves, Sharing the planet" (IBO, 2018b).

In Turkey, 36 schools offer PYP the education service (IBO, 2020). The IBEC education program is a certificate program offered in a private university in Turkey that provides education opportunities to educators (teachers/education faculty students) who want to be PYP teachers. The program, which began in February 2019, consists of six classes: "Curriculum Development, IB Philosophy and Teaching Methods, IB and Material Development, IB and Measurement Assessment, Social Responsibility, Teaching Implementation and Occupational Development". These classes are prepared in consideration of the PYP curriculum framework and learning outcomes.

\section{Instructional Design, Implementation and Assessment Process}

Teachers gain the knowledge and skills for developing a transdisciplinary inquiry program within the content of the curriculum development course. With this course, prospective teachers are expected to achieve learning outcomes such as "Understand the concept of integrated curriculums and design a transdisciplinary teaching-based curriculum", "Plan activities for an inquiry-based curriculum approach" and "Understand shareholder roles in the curriculum development process and complete requirements of cooperation". In the transdisciplinary instruction lesson plan preparation, teachers do not follow a randomised path. On the contrary, a 3-step "Instruction Design Step Organization, Implementation and Assessment Process" is followed: 


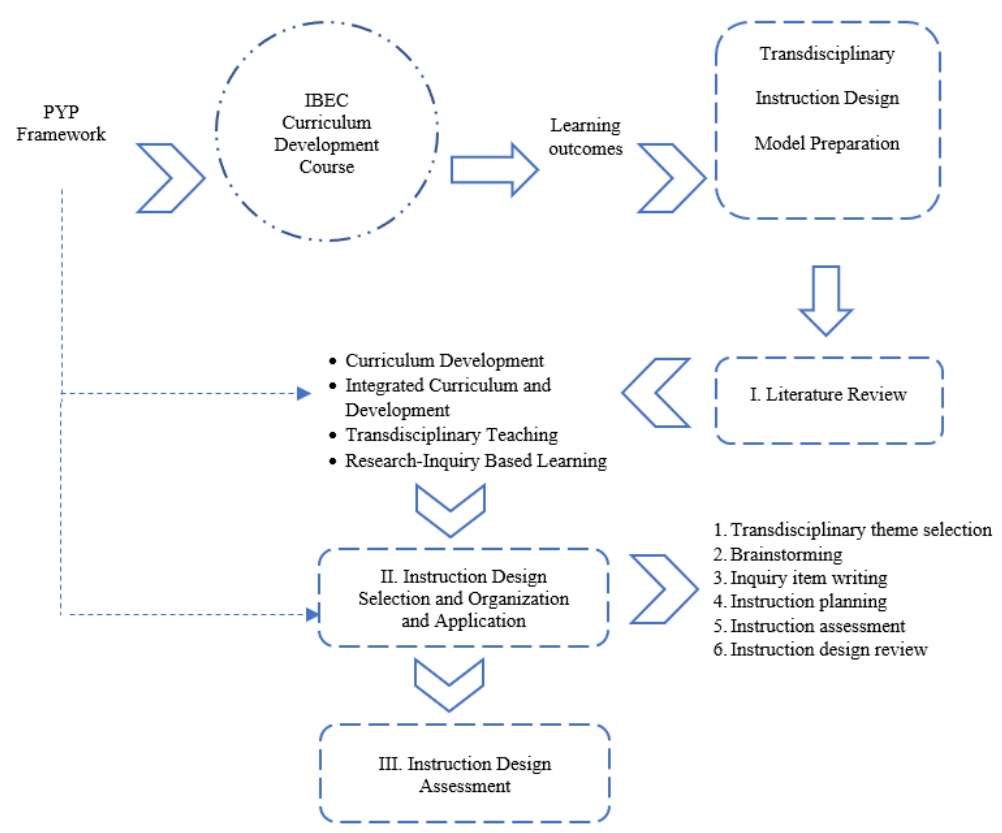

Figure 1. Instruction design step organization, implementation, and assessment process.

(1) Literature review: This step involves a literature review for the preparation of the curriculum. In this study, the topics related to the PYP framework such as program development, integrated program and design, transdisciplinary teaching, researchinquiry based learning were investigated. After the literature review, instruction design steps are determined and organised. The key education approach can be applied to develop other transdisciplinary programs apart from PYP education. A framework can be established through performing necessary reading tasks and assessments.

(2) Instruction design selection and organization and application: This includes the steps to prepare transdisciplinary curriculum. The literature review for this study found there are no direct design recommendations for guiding the preparation of teachers' transdisciplinary instruction. Thereupon, interdisciplinary, multi- disciplinary program designs were thoroughly assessed before the study (Erickson, 1995; Jacobs, 1989; Newell, 1994). Then, a 6-step transdisciplinary program design process was developed by the researcher. In this step, the PYP framework was effective. The PYP framework was effective at this step. Accordingly, the framework of the program design was structured based on the principles of "following themes; thinking, research and inquiry-based approach; teaching design-assessment". And the teachers applied those steps separately. The 6-step process is as follows:

i. Transdisciplinary theme selection: At this step, PYP themes and their duration are determined. Lesson learning outcomes are clarified at this stage. The transdisciplinary integrated program is based on thematic teaching, so it should be prepared thematically in other studies. Themes can be selected and edited by teachers.

ii.Brainstorming: This is the stage where elements such as the main idea, key concepts, connected concepts, learner profile, attitude and actions are determined with cooperation under PYP lesson plans. This stage is critical to 
the direct instruction process. It is the stage in which the program design elements are clarified and it may vary for the integrated programs.

iii.Inquiry item writing: This stage determines which topics under the theme students will make inquiries into. Teachers write a line of inquiry based on their experience. They guide the instruction process with subjects for inquiry. The inquiry process is the stage where unit concept, skill, action, and attitude elements are gained, in this regard it must be holistic and balanced. When inquiry items are written, learner properties (interest, curiosity, mental development, readiness etc.) must be considered. All periodic properties, such as cognitive levels, psycho-social characteristics, ethnicity, etc., of the age groups are among the important inputs in curriculum development. Whilst preparing transdisciplinary programs, there should be a "student inquiries" section as teaching is based on research and inquiry, and student questions are valuable. For this reason, it is suggested that the content of teaching is to be organized considering the students' questions in all transdisciplinary programs.

iv.Instruction planning: This is the stage where student-centric teaching activities are prepared, and materials are developed or designed. At this stage, it is important to consider that activities are based on constructivist, active learning, and research-inquiry basis.

v.Instruction assessment: This stage involves process-oriented measurement and assessment tool preparation.

vi.Instruction design review: At this stage, the "Inquiry Unit Rubric" is used for transdisciplinary instruction lesson assessment. At this stage, an "Inquiry Unit Rubric" is used for transdisciplinary unit assessment within the context of PYP. It is recommended to review the design in other transdisciplinary curriculum development studies. The steps of the review in this process are left to the program designers' preferences.

(3) Assessment of the design process: Teachers' experiences regarding the design process of PYP curriculum were evaluated in this stage. It dealt with working on the desired experience and reinforcement of the design.

\section{Data resources and analysis}

The research studied the experience in the transdisciplinary instruction process of three different study groups. Data was obtained from researcher diaries, focus group interviews conducted after implementation and reflective texts from the three study groups. Table 2 below shows where the data was obtained for each Case. The data consists of 11 separate focus group interviews, 50 reflective texts and 3 researcher diaries.

Table 2. Data collected in three situation contexts.

\begin{tabular}{lll}
\hline Case I & Case II & Case III \\
\hline 13.04 .2019 & 20.04 .2019 & 23.11 .2019 \\
3 separate focus group interviews & 3 separate focus group interviews & 6 separate focus group interviews \\
10 reflective texts & 13 reflective texts & 27 reflective texts \\
1 researcher diary & 1 researcher diary & 1 researcher diary \\
& & Survey \\
\hline
\end{tabular}


The focus group interview is a qualitative data collection technique for analyzing attitudes, perceptions, beliefs, views, and experiences regarding a certain topic in detail (Then, Rankin, \& Ali, 2014; Wilkinson, 1998). In this study, focus group interviews were conducted with groups that completed the implementation and teaching design steps. Semi-structured interview form consisting of 6 questions was used in focus group interviews. In the focus group interviews, teachers were asked to share their experiences on the steps of "transdisciplinary theme selection, brainstorming, inquiry item writing, instruction planning, instruction assessment, instruction design review". For example, such questions were posed: "What are the positive and negative experiences you had while determining the transdisciplinary theme? Can you share?" Focus group interviews were conducted in an order using fast note-taking techniques. Once the interviews were completed, researcher notes were read to the group members in order to clarify and confirm their ideas.

Reflection represents actions where learners assess their learning outcome achievement level for certain contexts and make decisions about the results. In this study, participants were asked to assess the implementation day with reflective texts.

Researcher dairies are an important data resource where a researcher's views and actions are noted within the scope of the research topic. During the research period, researchers took necessary notes while observing the study group instruction design process.

Qualitative data obtained from this study was analysed using thematic analysis. The data obtained from every question context during the focus group interviews was analysed. Related themes were formed for each question/context. Data obtained from researcher diaries and reflective texts was used for added depth.

\section{Validity and reliability}

Yin (2008) discusses the validity and reliability roles of multiple data sources in case studies. Data collected from multiple sources using interviews, reflective texts and researcher diaries ensures control of the depth and consistency of the obtained data.

The data obtained from focus group interviews was analysed using content analysis, creating codes and themes. Related codes and themes were controlled by two researchers. Concordance between the researches was analysed with " $(P(\%$ of consensus\% $)=[\mathrm{Na}$ (Consensus) / Na (Consensus) $+\mathrm{Nd}$ (Disagreement)] X100)" reliability formula (Miles \& Huberman 1994, p. 64). According to Miles and Huberman (1994), 80\% of concordance must be required for coder reliability. In this study, coder concordance was calculated as .86. These results show that coding for qualitative data is reliable.

Since participants' comments include multiple views, separate quotes are not presented for each code. Quotes are selected to include codes and related themes. In these quotes, "P" represents participants and "P1- G2" represents participant 1, group 2.

\section{Findings}

In the study, the participants prepared the transdisciplinary integrated program according to a six-step instructional design model. Participants' experiences related to the process (advantages, challenges) were presented in accordance with the model steps, respectively. 


\section{Step I: Transdisciplinary theme selection}

At this step, transdisciplinary theme and teaching duration decisions were made. Experiences about the decisions were analyzed. The teachers' experiences regarding decisions were emphasised and experiences were analysed. After the analysis, three different themes were identified: "who is at the centre $(f=38)$, group work and dynamic $(f=36)$, theme scope and student property $(f=23)$ ".

\section{Who is at the centre?}

The most striking point in the analysis was to determine "who is at the centre" when themes are selected. This theme was especially visible in groups with primary school teachers. Primary school teachers' theme selection created adaptation and senseof-belonging issues in the majority of the branch teachers. Most of the branch teachers perceived this as a facilitator factor. It was perceived as a facilitating factor for other infield teachers. When primary school teachers and branch teachers selected the theme together, they were able to achieve harmony and support of the branch teacher was enabled.

\section{Group work and dynamics}

When teaching programs were prepared, the "importance of group work and dynamics" was one of the emphasised issues. Participants reported that group work facilitated plan preparations, made problems easier to solve, fostered learning together and expanded the knowledge area. In particular, participants felt that group members' openness to different ideas facilitated the process.

\section{Theme scope and student property}

Duration of transdisciplinary instruction was linked with "theme scope and student property". If the number of subjects in the themes was high, teaching of the unit was expanded. Students' ages influenced how much they focus on units.

Researcher diary notes from 13/04/2019 and 23/11/2019 and quotes from P4-G1, P46G11, P16 and P30 coded teachers that include these themes are as follows:

"...As I can see, group work is successful and it seems to continue like that. They listen to each other, there is an effective discussion environment between the groups. I believe this will positively

Researcher reflect on the plan..." (13.04.2019)

diary "...Teachers do not have a problem in terms of themes. They selected quickly. Age group was the common decisios of almost all groups... I see that groups of primary school teachers are more dominant and active in groups with more primary school teachers. Some of the branch teachers are listeners ..." (23.11.2019) "At this point, openness to different ideas enabled ideas to change when the process ended and this facilitated the process." (P4-G1) "Since primary school teachers decided on how long the

Focus group transdisciplinary theme would last, there was no problem in group interview work. During group work, we thought about what we could do related to the theme in our field and shared this in the group. We realised that selecting the theme and the duration of all branch teachers was more beneficial." (P46- G11) 
Reflective text
"When we determined our theme, we simplified the subjects by considering our age group. We need to consider the age group and level." (P16)

"I did not feel I belonged to the group since primary school teachers determined the theme beforehand. I struggled to see how to adapt the theme to English classes and how to mention the transdisciplinary theme." (P30)

\section{Step II: Brainstorming}

At this stage, elements that are the key point of the entire program such as main idea posing, learner profile identification or concept-skill-attitude-action posing were determined with brainstorming. Experiences in this process are observed and analysed. At the end of the analysis, five different themes were determined: "the hardest stage: determining the main idea $(f=43)$, group work and dynamic $(f=33)$, the most enjoyable stage: whole-piece-whole $(f=31)$, brainstorming and innovation $(f=27)$, different discipline unity $(f=17)$ "

\section{The hardest stage: Determining the main theme}

The findings of this study showed that most participants found the main idea of finding and expressing in objective form the hardest stage. Since the main idea guides the learning outcomes, line of inquiry and other elements and activities, this topic requires more attention. Participants said that other elements were identified more easily when the main theme was written. Teachers spent a lot of time on this stage.

\section{Group work and dynamics}

The importance of group work was emphasised at this stage. It was shared that group work strengthened communication and accelerated the process.

\section{The most enjoyable stage: Whole-piece-whole}

The main theme determination of the unit was seen as the hardest stage. Participants perceived detecting other elements based on the main idea and linking these to the main idea as enjoyable after writing the main idea. They thought this process resembled a puzzle.

\section{Brainstorming and innovation}

Participants spoke of the benefits of this stage of the process. They stated that creative ideas and views that would make the lesson plan different emerged.

\section{Different discipline unity}

Different branch/discipline teachers' working together was perceived positively. According to participants, interdisciplinary interaction was provided, and the needs of all disciplines were considered.

Researcher diary notes from 13/04/2019 and quotes from P15-G5, P1, P21 and P37 coded teachers that include these themes are as follows: 
“...Group work is working effectively. They are working intensively.

Researcher Focus is achieved. Almost everyone is giving their opinion... They diary struggle when they are writing down the main idea. They asked for my help a couple of times... This stage took a bit longer. I will see how this situation reflects on other stages. (13/04/2019)

"Transdisciplinary theme of the units offers us a wide range of options. Topics in these options are connected and valuable. It is challenging to select the main theme and pose an activity based on Focus group that path, because the properties and criteria of the main idea are interview important. After determining the main idea, other processes start to shape up. It is easier to draw our path. Learner profile, concepts and writing line of inquiry were challenging in our first plans. By the end, it was easier as these concepts are better understood." (P15- G5) "I struggled to write the main idea and to express this in an unbiased way." (P1)

Reflective "After determining the main idea, determining, and creating (the text learner profile, concepts etc.) was easy for me. Actually, this was the most enjoyable part of the plan. I felt like I was making a puzzle. In the end, I had problems with inserting them into the plan. But now I think I understand them." (P21)

"I completed the task without any trouble. Group work increased the quality of brainstorming and ideas. Sharing ideas between the branches supported the implementation of my branch." (P37)

\section{Step III: Inquiry item writing}

At this stage, groups thought about what to inquire about regarding their teaching program and tried to write them down. Participants' experiences at this stage were observed and assessed. As a result of the analysis, five different themes were found: "connections with the main idea $(f=35)$, group work and dynamics $(f=30)$, brainstorming: manufacturing $(f=18)$, student-centric approach $(f=15)$, individuality against the group $(f=13) ”$.

\section{Connections with the main idea}

Inquiry items must be connected with the main idea. The majority of the participants said that they struggled to find inquiry subjects related to the main idea. In the previous stage, the main struggle was writing up of the main idea. The comprehensiveness of the main idea was reflected in discipline determination. Participants struggled to pose inquiry topics that were related to the main idea and evaluated the problem from their own contexts.

\section{Group work and dynamics}

As in other steps, the positive contribution of group work was visible at this stage. Participants said that making common decisions, idea exchanges, working with different branches were positive contributions and facilitated determination of inquiry topics. 


\section{Brainstorming: Manufacturing}

Determining what students will inquire into is about creating. In this context, participants said that brainstorming is an important mediator in determining the line of inquiry.

\section{Student-centric approach}

Participants said that they struggled to write down age-group appropriate lines of inquiry and thinking for the students.

\section{Individuality against the group}

Other than group work and cooperation, participants felt there were challenges when individuality was emphasised among the participants.

Researcher diary notes from 23/11/2019 and quotes from P20-G5, P29-G7, P19 and P33 coded teachers that include these themes are as follows:

Researcher "This stage went more easily than the previous stage. I can see that diary they are trying to consider the main idea and disciplines when writing down inquiry items..." (23.11.2019)

"After creating the main idea as a group, it was easier to determine the rough disciplines. But sometimes we did not adapt ourselves to

Focus group the age group when we prepared or created inquiry questions. But interview this problem was overcome with different perspectives." (P20-G6).

"We moved forward easier when we determine the inquiry items as we had already determined the main idea. At the same time, we had thought about the line of inquiry that would shed light on in-class activities. Inquiry items led to activities and activities led to a line of inquiry." (P29-G7)

"...Brainstorming itself is beneficial for knowledge creation..." (P15)

"When preparing the course plan, I was confused when it came to Reflective relating the different disciplines. I struggled to connect the multiple text disciplines and the different disciplines did not look good." (P19)

"Individuality was prominent when creating the inquiry items and group work was challenging. Thence, I always struggled.” (P33)

\section{Step IV: Instruction planning}

At this stage, groups prepared transdisciplinary instruction-based activities. The focus was on teaching the determined line of inquiry. Participants' experiences at this stage were observed and assessed. After the analysis, six different themes were identified: "imagination ( $f=35)$, group work and dynamics $(f=32)$, challenging step $(f=23)$, being the teacher of the same age group $(f=13)$, preparing research cycle $(f=11)$, integration of branch courses $(f=10)$ ". 


\section{Imagination}

One of the most important things required to ensure development in teaching planning was believed to be imagination. Participants said that they used their imagination to generate creative ideas and enriched the plan.

\section{Group work and dynamic}

Participants found that group work was beneficial and enjoyable for lesson planning. Various views were obtained such as working with different disciplines facilitated planning, idea sharing provided feedback, it was possible to comment on the validity of the activities and to discuss the applicability of branch activities, intragroup discussions clarified planning and idea generation from ideas was possible. Nevertheless, participants believed that generating a high number of ideas was challenging for decision making.

\section{The challenging step}

This is where the research-inquiry cycle of the teaching plan is prepared. Studentcentric teaching methods and technique application activities are planned. At this stage, participants said that they struggled to pose activities, to connect the activities with themes, to use different methods and techniques alongside posing activities for the main idea. In addition to these, participants uttered that activity development is timeconsuming, it calls for thinking and there is a need for teacher development. Higher student-centric methods and technical knowledge meant richer teaching planning. Participants pronounced the benefits of knowing student-centric methods to achieve the main idea.

\section{Being a teacher of the same age group}

Being teachers of the same age group was thought to be beneficial in terms of teaching planning owing to the fact that teachers have similar experiences when they teach at the same level. This leads to achieving a common language.

\section{Preparing a research cycle}

Some participants felt there were challenges in research cycle planning and especially in preparing activities for students to discover knowledge. Moreover, participants spoke of the facilitator side of the roadmap provided by the research cycle in lesson plan preparation.

\section{Integration of branch courses}

Branch teachers in the group mentioned two main topics. The first was the problem of linking learning outcomes of the branch classes to the main idea, the second was the easy process preparation with parallel activities.

Researcher diary notes from 20/04/2019 and quotes from P30-G8, P42-G12, P23 and P41 coded teachers that include these themes are as follows:

"Groups are working in harmony at the teaching planning stage.

Researcher Teachers' knowledge of methods seems to work here. Group reactions diary to different activities are good... There are teachers who do source reading and internet research etc. I think they are trying to adapt 
activities...There are some confused teachers...” (20.04.2019) Focus effective knowledge and opinion sharing with primary school teachers group and other branch teachers. In this sense, I cannot think of concurrent interview planning." (P30-G8)

"Activity writing and material development are more effective and efficient with different teachers working with the same age group." (P42G12)

"At this stage, I struggled a bit. I was indecisive when creating activities. I included the activities that would best fit the main idea." (P23)

Reflective "Here, we need to make research inquiry-based planning in a studenttext centric way. This was the point that improved my imagination. Posing activities for different fields is a type of 'challenge' for me. I think this is what I must develop the most." (P41)

\section{Step IV: Instruction assessment}

At this stage, work on how to assess student performances was carried out by the groups. Participants' experiences at this stage were observed and assessed. After analysis, five different themes were identified: "learning student-sustaining activities $(f=28)$, group work and dynamics $(f=27)$, challenging step $(f=23)$, performance assessment method knowledge $(f=21)$, brainstorming $(f=13)$ ".

\section{Learning student-sustaining activities}

At the instruction assessment stage, gaining information about the student using individual recognition techniques and sustaining activity was found to be beneficial.

\section{Group work and dynamics}

One of the facilitator effects for attaining the assessment stage is group work. It was found that cooperation enriched assessment method development and was regarded as beneficial by the participants as is shows the correct path.

\section{Challenging step}

One of the most challenging steps identified by participants was the teaching assessment step. This step was found challenging due to the teacher planning, the reading required, the outcomes being hard to measure such as skill-attitude, the different learner properties, the challenging method selection, the requirement of effort and the challenges of the visual organiser and assessment tool preparation.

\section{Performance assessment method knowledge}

Teaching is assessed with process-based methods. Participants said that they need method versatility to assess student performance, they need to know how to use these methods and they felt they had insufficient knowledge and experience. 


\section{Brainstorming}

Participants benefited from brainstorming at the instruction assessment stage as they were able to create different alternatives and easily come up with a solution.

Researcher diary notes from 20/04/2019 and quotes from P36-G10, P45-G11, P2 and P29 coded teachers that include these themes are as follows:

"In general, they are in a good state. But sometimes they have problems

Researcher amongst themselves with how to make 'process' based assessment. I diary think they need more information. They do not have a disagreement. Group work is effective." (20/04/2019)

"Process assessment is a bit challenging. Each student has different interests, ambition, desires and learning speed. As teachers, we tried not

Focus to leave out any student or level of effort." (P36-G10)

group "Assessments as the branch help us to find a common understanding as interview to whether the desired results are achieved with that theme. Whence, we can carry the implementations with good results to the next theme." (P45-G11)

"At the end of the assessment period, I struggled and forgot to include it Reflective in the process as I am used to doing." (P2)

text "In assessment, we cooperated with my group members. Ifelt insufficient nonetheless I think I improved myself with this step. I will continue to improve." (P29)

\section{Step VI: Instruction design review}

At this stage, groups reconsider the plans they have developed with an inquiry rubric. Participants' experiences at this stage were observed and assessed. As a result of the analysis, three different themes emerged: "providing feedback $(f=36)$, group work and dynamics $(f=23)$, roadmap $(f=21)$ ".

\section{Providing feedback}

Issues such as the benefits of noticing insufficiencies and errors in the plan, meeting student needs and expectations, clarifying question marks in the plan, controlling the applicability of the plan, lesson plan improvement and obtaining realistic results were mentioned in relation to the reconsideration of the prepared teaching design.

\section{Group work and dynamic}

With group work, the opportunity for detecting insufficiencies and correcting errors was emphasised.

\section{Roadmap}

Participants mentioned that using the inquiry rubric enabled a systematic approach and provided a roadmap for the teacher.

Researcher diary notes from 13/04/2019 and quotes from P7-G2, P28-G7, P3 and P19 coded teachers that include these themes are as follows:

"They reconsidered teaching design by using the rubric they had. I Researcher observed that they noticed their insufficiencies and changed based on 
diary them. In general, this stage is positive. It is not regarded as useless. This is a good sign for curriculum development." (13/04/2019)

Focus

"We had the chance to realise and change some insufficiencies. But in

group general, we did not observe any insufficiencies." (P7-G2)

interview

"At plan reconsideration stage, we were able to think about what we did and what else we could do. This acted as feedback so we spotted our insufficiencies." (P28- G7)

"The rubric was an amazing tool. We were able to find a lot of answers to Reflective unanswered questions and better understand them. Control with a rubric text makes our work more systematic and easier. To this end, I did not struggle to make use of this. It facilitated my work." (P3)

"In plan preparation, I struggled the most to understand how to assess and what to use in the meantime. At this stage, I was able to see which criteria we needed to use to create the plan." (P19)

\section{Discussion and Conclusion}

Teacher cooperation is almost mandatory in curriculum planning and implementation when the curriculum is not prepared by a central body. The transdisciplinary integrated curriculum must be designed by enriching it with different perspectives. Thus, students can learn from a broader perspective. Dobozy and Dalziel (2016) stated that transdisciplinary pedagogical templates, which were not specific to any discipline, guided educators in the process of designing and offered various advantages. In this study, participants were asked to prepare a transdisciplinary instruction lesson plan by following a 6-step instruction design model. Thus, it was thought that teacher experiences related to the design process could be followed and evaluated systematically. It is also believed that the design model used in this research can be applied to the design of other transdisciplinary programs. Observations also proved that following the model guided teachers about how to act at each stage, which brought permanence and coherence to the process.

One of the most striking points in this study is the emphasis on the importance and necessity of group work in almost all steps of transdisciplinary instruction preparation. Teachers appreciated the power of making decisions together. Tallman (2019) underlines that collaboration provides teachers with the opportunity to think about their practices and to question their teaching approaches, which supports their professional development. He also suggests that teachers can be comfortable and frank because they trust their collaborative partners.

Bergeron and Dean (2013) state that IB teachers value cooperation during the planning process. The transdisciplinary approach requires melting multiple disciplines in the same pot. Therefore, activities are multidimensional and deep. Different branches and different perspectives can enrich all the time to ensure both development and change along with facilitation of planning. Cooperation-based planning is necessary for transdisciplinary learning and teaching, increases teacher competence (Cook 2015; Miller, 2013; Savage \& Drake, 2016; Tan \& Nashon, 2015) and it has positive effects on teaching applications of PYP experience according to teachers (Walsh \& Casinader, 2018). It is clear, therefore, that when transdisciplinary instruction lesson plans or curriculums are prepared, it is important to bring together teachers from different disciplines and to encourage them in 
this respect.

Designing a transdisciplinary program is directly about benefiting from a collaboration culture. Nevertheless, there can be teachers who are unable to utilize from the process in a short time. Indeed, specifically the in-field teachers admitted that they experienced belonging problems and could not benefit from the group work decently. General structure by primary or pre-school teachers in transdisciplinary instruction preparation was seen both as a challenge and a facilitator in different cases. The common action of all teachers is important for executing this plan. There might be branch course integration problems when primary school or pre-school teachers are dominant. This result makes cooperation among different branch teachers responsible for the teaching of the same age group mandatory for transdisciplinary instructions. Because, interdisciplinary horizontal and vertical integrations are necessary for the design of transdisciplinary instructions (Drake et al. 2015). Tasker, Johnson and Davis (2010) state that individuals can organize themselves by questioning themselves when supported by their groups. Otherwise, Keiny (1993) highlighted the role of reflective teacher in supporting the professional development. It is indicated that it takes about a year for teachers to become a reflective teacher by participating in school activities. Therefore, it takes time to ensure the productive work of groups and meeting of group members' expectations. The creation of such a culture can spread over time.

Another remarkable situation in this study was to see the main idea as the main structure of the curriculum. Participants said that they struggled with writing down the main idea but it was easier to prepare a line of inquiry and activities after creating the main idea. In a similar vein, Savage and Drake (2016) state that teachers find the main idea and other elements based on the main idea complex when a PYP plan is prepared. Main ideas carry the comprehensive properties of the concept, attitude, skill, learner profile, line of inquiry and so on indicating the final target that the students will reach. Main ideas must be transdisciplinary and comprehensive enough to have multiple learning outcomes. The planning stage must be emphasised in determining the main idea. Therefore, participants spend more time and effort thinking about the next steps. This is normal. After the main idea, connections are formed between all other elements, its position in the whole becomes clear and plan formation becomes an enjoyable attempt. Therefore, all elements in the curriculum are emphasised.

Instruction planning and assessment, research-inquiry-based activity determination, posing lines of inquiry were other challenging situations for the participants. Teachers' occupational knowledge and skills were visible at these stages. How to conduct a processbased assessment, how to organise student-centric activities, how to ensure requiredinquiry-based teaching are other areas that teachers need the knowledge of. If there is missing or insufficient learning, it is natural to struggle in enriching the process. Drake et al. (2015) report that some teachers feel inexperienced in PYP planning; therefore, negative attitudes might be observed. Medwell, Cooker, Bailey and Winchip (2017), state that teachers must start research-based work within the interest area of the students. In this study, which age group will be considered for teaching planning was regarded as a problem. Knowing students' mental and psychological development and their areas of interest play an important role in activity selection and organisation.

One of the other useful practices for teachers in designing instruction was the brainstorming technique. Brainstorming is a group work technique that includes 
generating ideas and decision making fast. It also requires mental flexibility as it is based on imagination. Panaritis (1995) stressed the importance of being patient and flexible so as to develop an effective and quality curriculum. In this study, teachers had difficulties in writing inquiry items, planning and evaluating the teaching and had to deal with these challenges. The brainstorming techniques might have helped them overcome these challenging situations. It may have provided safe setting in which teachers expressed their opinions comfortably, and various ideas appeared from each other. Besides, the use of brainstorming technique may have prevented the domination of a certain person in the group and created an affective pleasure. Thus, teachers may have strongly suggested the use of the brainstorming technique. Obviously, the application of the brainstorming technique is not recent, and the results are not surprising. The result of this research may emphasise that the brainstorming technique can be applied to all steps of designing a curriculum.

Curriculum development approaches must ensure implementation sharing, innovative design idea processing and reconsidering (Dempster, Benfield \& Francis 2012). Regardless of the prepared curriculum or lesson plan, it is important to reconsider them before implementation. Thus, any insufficiencies or errors can be solved, and applicability can be checked. In the present study, participants express that reconsidering the instruction design provided feedback on lesson plan organisation and constituted a roadmap. In this sense, all prepared plans must be controlled, and a pilot study may be recommended. In the research, the process of preparing a transdisciplinary integrated curriculum was examined through a case study via a design. In other studies, the problems arising in the application of the design model used in the current research can be eliminated and improved through action research. In addition, by using the same model in the preparation of different integrated curriculums independent of PYP, the intellectual and affective effects of the model on teacher development can be emphasized.

\section{References}

Akins, A., \& Akerson, V. L. (2002). Connecting science, social studies, and language arts: An interdisciplinary approach. Educational Action Research, 10(3), 479-498. doi:10.1080/09650790200200196.

Amaliyah, N., Sapriya, S., \& Maryani, E. (2007). A trans-disciplinary approach and inquiry-based learning model of social studies. World Transactions on Engineering and Technology Education, 15(2), 174-177.

Augsburg, T. (2014). Becoming transdisciplinary: The emergence of the transdisciplinary individual. World Futures, 70(3-4), 233-247. doi: 10.1080/02604027.2014.934639.

Beane, J. S. (1995). Curriculum integration and the disciplines of knowledge. The Phi Delta Kappan International, 76(8), 616-622.

Berferon, L., \& Dean, M. (2013). The IB teacher professional: Identifying, measuring and characterizing pedagogical attributes, perspectives, and beliefs. Retrieved from https://www.ibo.org/globalassets/publications/ib-research/

Berger, G. (1970). Interdisciplinarity: Problems of teaching and research in universities. Retrieved from http://fileeric.ed.gov/fulltext/ED061895.pdf

Bintz, W. P., \& Monobe, G. (2018). Interdisciplinary curriculum: Using poetry to integrate reading and writing across the curriculum. Middle School Journal, 49(3), 36-48. doi: 10.1080/00940771.2018.1439667 
Boyer, E. L. (1995). The educated person. In J. A. Beane (Ed.), Toward a coherent curriculum (16-25). Alexandria, VA.: Association for Supervision and Curriculum Development.

Broersma, C. (2014). Is it time to change? Infusing the transdisciplinary approach into social work studies. Journal of Sociology and Social Work, 2(2), 145-154. doi: $10.15640 /$ jssw.v2n2a9

Brough, C. J. (2007). Nurturing talent through curriculum integration. Kairaranga 8(1), 8-12. Retrieved from https://files.eric.ed.gov/fulltext/EJ914608.pdf

Brough, C. J. (2012). Implementing the democratic principles and practices of studentcentred curriculum integration in primary schools. Curriculum Journal, 23(3), 345-369. doi: 10.1080/09585176.2012.703498

Bruner, J. (2009). Eğitim süreci [The process of education] (Trans. T. Öztürk). Ankara: Pegem Publishing.

Campbell, A. (1999). An integrated curriculum for English, media and drama at Ks 4. English in Education, 33(1), 13-23. doi: 10.1111/j.1754-8845.1999.tb00159.x

Campbell, D. T. (1969). Ethnocentrism of disciplines and the fish-scale model of omniscience. In M. Sherif and C. W. Sherif (Eds.), Interdisciplinary Relations in the Social Sciences (328-348). Chicago, IL: Aldine.

Choi, B. C. K, \& Pak, A. W. P. (2006). Multidisciplinarity, interdisciplinarity, and trandisciplinarity in health research, services, education, and policy: 1 . Definitions, objectives, and evidence of effectiveness. Clinical Investigative Medicine, 29(6), 351-364.

Cook, S. (2015). A study of the perceptions of International Baccalaureate Primary years programme teachers on factors influencing their development as PYP educators. Retrieved

from https://www.ibo.org/contentassets/4ccc99665bc04f3686957ee197c13855/saman tha-cook-pyp-en.pdf

Dempster, J. A., Benfield, G., \& Francis, R. (2012). An academic development model for fostering innovation and sharing in curriculum design. Innovations in Education and Teaching International, 49(2), 135-147. doi: 10.1080/14703297.2012.677595

Dobozy, E., \& Dalziel, J. (2016). Transdisciplinary pedagogical templates and their potential for adaptive reuse. Journal of Interactive Media in Education, (1)8, 111. doi: $10.5334 /$ jime.402

Drake, M. (2007). Creating standarts-based integrated curriculum: Aligning curriculum, content, assessment and instruction. California: Corwin Press

Drake, M., \& Burn, R. C. (2004). Meeting standarts through integrated curriculum. Alexandria, Va.: Association for Supervision and Curriculum Development.

Drake, S. M., Savage, M. J., Reid, J. L., Bernard, M. L., \& Beres, J. (2015). An exploration of the policy and practice of transdisciplinarity in the IB PYP. Retrieved from http://www.ibo.org/globalassets/publications/ibresearch/pyp/anexploration-of-the-policy-and-practice-of-transdisciplinarity-in-the-pypfinalreport.pdf

Erickson, H. L. (1995). Stirring the head, heart, and soul: Redefining curriculum and instruction. California: Corwin Press, Inc.

Ferguson-Patrick, K, Reynolds, R., \& Macqueen, S. (2018). Integrating curriculum: A case study of teaching global education. European Journal of Teacher Education, 41(2), 187-201. doi: 10.1080/02619768.2018.1426565 
Fogarty, R., \& Stoehr, J. (1995). Integrating curricula with multiple intelligences: Teams, themes, and threads. Arlington Heights, Illinois: SkyLight Professional Development.

Getchell, L. A. (2010). Effects of International Baccalaureate primary years programme on teacher philosophy, perceptions of efficacy, and outlook on education (Unpublished doctoral dissertation). University of Denver, Denver, Colorado.

Gibbons, J. A. (1979). Curriculum integration. Curriculum Inquiry, 9(4), 321-332. doi: $10.1080 / 03626784.1979 .11075614$

Giri, A. K. (2002). The calling of a creative transdisciplinarity. Futures 34(1), 103-115. doi:_10.1016/S0016-3287(01)00038-6

Hammond, D. J. (2017). An investigation into the impact of an integrated curriculum on learning in the primary school (Unpublished doctoral thesis). Durham University, Durham.

Herro, D., \& Quigley, C. (2017). Exploring teachers' perceptions of STEAM teaching through professional development: Implications for teacher educators. Professional Development in Education, 43(3), 416-438. doi: 10.1080/19415257.2016.1205507

Holeva, L. C. (2012). The effects of the International Baccalaureate primary years programme on teacher's philosophy of education and instructional practices (Unpublished master thesis). California State University, California.

Huizinga, T., Handelzalts, A., Nieveen, N., \& Voogt, J. M. (2014). Teacher involvement in curriculum design: Need for support to enhance teachers' design expertise. Journal of Curriculum Studies, 46(1), 33-57. doi: $10.1080 / 00220272.2013 .834077$

International Baccalaureate Organization (IBO). (2018a). PYP planner. Cardiff, UK: International Baccalaureate.

International Baccalaureate Organization (IBO). (2018b). Learning and teaching. Cardiff, UK: International Baccalaureate.

International Baccalaureate Organization (IBO). (2020). Find an IB world school. Retrieved from https://www.ibo.org/programmes/find-an-ib-school/

Jacobs, H. H. (1989). The growing need for interdisciplinary curriculum content. In H. H. Jacobs (Ed.), Interdisciplinary curriculum: Design and implementation (1-12), Alexandria, Va.: Association for Supervision and Curriculum Development.

Jacobs, H. H. (1991). Planning for curriculum integration. Educational Leadership, 49(2), 27-28. Retrieved from https://eric.ed.gov/?id=EJ432777

Jeder, D. (2014). Transdisciplinarity- the advantage of a holistic approach to life. Procedia- Social and Behavioral Sciences, 137(2014), 127-131. doi: 10.1016/j.sbspro.2014.05.264

Keiny, S. (1993). School-based curriculum development as a process of teachers' professional development. Educational Action Research, 1(1), 65-93. doi: $10.1080 / 0965079930010105$

Kysilka, M. L. (1998). Understanding integrated curriculum. Curriculum Journal, 9(2), 197-209. doi: 10.1080/0958517970090206

LaMotte, M. (2018). The integrated approach versus the traditional approach: Analyzing the benefits of a dance and transportation integrated curriculum. Journal of Dance Education, 18(1), 23-32. doi: 10.1080/15290824.2017.1336667

Marshall, J. (2014). Transdisciplinarity and art integration: Toward a new understanding of art-based learning across the curriculum. Studies in Art Education, 55(2), 104127. doi: 10.1080/00393541.2014.11518922 
Mathison, S., \& Freeman, M. (1997). The logic of interdisciplinary studie. Chicago Annual Meeting of the American Educational Research Association. Retrieved from http://eric.ed.gov./?id=ED418434.

McGuinness, C., Swartz, R., \& Sproule, L. (2016). Student thinking and learning in the PYP transdisciplinary framework: Case study from PYP schools. Retrieved from https://resources.ibo.org/data/g_0_ibres_sup-dr_1610_1b_e.pdf

McPhail, G. (2018). Curriculum integration in the senior secondary school: A case study in a National Assessment Context. Journal of Curriculum Studies, 50(1), 56-76. doi:10.1080/00220272.2017.1386234

Medwell, J., Cooker, L., Bailey, L., \& Winchip, E. (2017). The impact of the PYP exhibition on the development of international-mindedness, critical thinking and attributes of the IB learner profile. Retrieved from https://resources.ibo.org/pyp/topic/Studies-exploring-programmeimplementation/?

Meeth, R. L. (1978). Interdisciplinary studies: A matter of definition. Change: The Magazine of Higher Learning, 10(7),10. doi: 10.1080/00091383.1978.10569474

Miles, B. M., \& Huberman, A. M. (1994). Qualitative data analysis. California: SAGE Publication, Thousand Oaks.

Miller, B. A. (2013). Joining forces: A collaborative study of curricular integration. International Journal of Education and the Arts, 14(special issue), 1-24. Retrieved from https://files.eric.ed.gov/fulltext/EJ1012892.pdf

Newell, W. H. (1994). Designing interdisciplinary courses. New Directions for Teaching and Learning, 1994(58), 35-51. doi: 10.1002/t1.37219945804

Nicolescu, B. (2012). The need for transdisciplinarity in Higher Education in a globalized world. Transdisciplinary Journal of Engineering and Science 3, 11-18. doi: 10.22545/2012/00031

Nolan, P., \& McKinnon, D. (2003). Enhancing the middle in a New Zealand secondary school: Integration, experiential learning, and computer use. International Journal of Educational Reform 12, 230-243. Retrieved from https://eric.ed.gov/?id=EJ852564

Özer, Ö. (2010). A case study on transdisciplinary approach of integrated curriculum: Perspectives of early childhood teachers (Unpublished master's thesis). Middle East Technical University, Ankara.

Panaritis, P. (1995). Beyond brainstorming: Planning a successful interdisciplinary program. The Phi Delta Kappan, 76(8), 623-628.

Park, J., \& Son, J. (2010). Transitioning toward transdisciplinary learning in a multidisciplianary environment. International Journal of Pedagogies and Learning, 6(1), 82-93. doi: 10.5172/ijpl.6.1.82

Romance, N. R., \& Vitale, M. R. (2001). Using in-depth science instruction to accelerate student achievement in science and reading comprehension in grades 1-2. International Journal of Science and Mathematics Education, (2012)10, 457472. doi:10.1007/s10763-011-9326-8.

Rosenfield, P. L. (1992). The potential of transdisciplinary research for sustaining and extending linkages between the health and social sciences. Social Science and Medicine, 35(11), 1343- 1357. doi: 10.1016/0277-9536(92)90038-R

Savage, M. S., \& Drake, S. M. (2016). Living transdisciplinary curriculum: Teachers' experiences with the International Baccalaureate's Primary Years Programme. International Electronic Journal of Elementary Education, 9(1), 1-20. 
Schumacher, D. H. (1995). Five levels of curriculum integration defined, refined, and described. Research in Middle Level Education, 18(3), 73-94. doi:10.1080/10825541.1995.11670055

Smith, K., Kulinna, P. H., Vissicaro, P., \& Fredrickson, L. (2016). Anthropology, dance, and education: Integrated curriculum in social studies. The Social Studies, 107(1), 28-37. doi: 10.1080/00377996.2015.1094725

Tallman, T. O. (2019). How middle grades teachers experience a collaborative culture: An interpretative phenomenological analysis. RMLE Online, 42(8), 1-16. doi: 10.1080/19404476.2019.1668103

Tan, Y. S. M., \& Nashon, S. M. (2015). Promoting teachers' collaborative exploration of a new science curriculum: The case of a Singapore learning study. Professional Development in Education, 41(4), 671-689. doi: 10.1080/19415257.2014.944670

Tasker, T., Johnson, K. E., \& Davis, T. S. (2010). A sociocultural analysis of teacher talk in an inquiry-based professional development. Language Teaching Research, 14(2), 129-140. doi: 10.1177/1362168809353871

Then, K. L., Rankin, J. A., \& Ali, E. (2014). Focus group research: What is it and how can it be used?. Canadian Journal of Cardiovascular Nursing, 24(1), 16-22. Retrieved from https://www.ncbi.nlm.nih.gov/pubmed/24660275

Tucker, B., Hafenstein,N. L., Jones, S., Bernick, R., \& Haines, K. (1997). An integratedthematic curriculum for gifted learners. Roeper Review, 19(4), 196-199. doi: $10.1080 / 02783199709553828$

Tudor, L. S. (2014). Perception of teachers on curriculum integration: Integration patterns practice. Procedia- Social and Behavioral Sciences, 127, 728-732. doi: 10.1016/j.sbspro.2014.03.344

Twigg, V. V. (2010). Teachers' practices, values and beliefs for successful inquiry-based teaching in the International Baccalaureate Primary Years Programme. Journal of Research in Education, 9(1), 40-65. doi: 10.1177/1475240909356947

United Nations Educational, Scientific and Cultural Organization (UNESCO). (1986). Interdisciplinarity in general education. Division of educational. Retrieved from https://unesdoc.unesco.org/ark:/48223/pf0000070823

Vars, G. F. (1991). Integrated curriculum in historical perspective. Educational Leadership, 49(2), 14-15. Retrieved from https://eric.ed.gov/?id=EJ432773

Wall, A., \& Leckie, A. (2017). Curriculum integration: An overview. Current Issues in Middle Level Education, 22(1), 36-40. Retrieved from https://files.eric.ed.gov/fulltext/EJ1151668.pdf

Walsh, L., \& Casinader, N. (2018). Transcultural capability and the Primary Years Programme. Retrieved from https://resources.ibo.org/pyp/topic/Studies-onstudent-and-school-outcomes/?

Wilkinson, S. (1998). Focus group methodology: A review. International Journal of Social Research Methodology, Theory and Practice, 1(3), 181-203. doi: 10.1080/13645579.1998.10846874

Williams, N. L., Connell, M., White, C., \& Kemper, J. (2003). Real boats rock: A transdisciplinary approach for teacher preparation. Action in Teacher Education, 24(4), 95-102. doi: 10.1080/01626620.2003.10463284

Yin, R. K. (2008). Case study research: Desing and methods. Thousand Oaks, CA: SAGE Publication

Yin, R. K. (2011). Qualitative research from start to finish. New York: The Guilford Press. 